\title{
Brasil, Inglaterra e Portugal: circulação de impressos protestantes no nordeste brasileiro
}

\author{
Ester Fraga Vilas-Bôas Carvalho do Nascimento ${ }^{1}$
}

\section{RESUMO}

Este trabalho apresenta a ação da Sociedade Bíblica Britânica e Estrangeira/BFBS no Brasil, durante o século XIX, especialmente no Nordeste, fazendo circular impressos protestantes. O referido texto tem o apoio financeiro do CNPq e integra o Projeto de Pesquisa coordenado por essa pesquisadora, intitulado Brasil, Portugal e Inglaterra: circulação de impressos protestantes e outros impressos durante os Oitocentos. A estratégia de distribuir impressos antecedeu à organização de escolas, com a finalidade de implantar definitivamente o Protestantismo no Brasil. Como essa estratégia teve sucesso num país que, na época, possuía uma população analfabeta em sua maioria? $\mathrm{O}$ que poderia ser visto como um problema era, na verdade, o diferencial. Quando o colportor, vendedor ambulante de impressos protestantes, chegava num determinado local que as pessoas não sabiam ler, ele propunha a organização de um grupo e se comprometia em enviar um professor para ensiná-los, que, na verdade também era um missionário. Dessa forma, eles mapearam no Brasil o território de instalação de suas futuras igrejas e escolas. A hipótese que defendo é que a intervenção de instituições protestantes na circulação e difusão de impressos possibilitou a definitiva inserção do Protestantismo no país. Este trabalho considera os impressos protestantes que circularam no Brasil e em Portugal a partir dos Oitocentos como Bibliotecas Pedagógicas Protestantes, as quais foram utilizadas como estratégias para a construção de uma civilização cristã protestante e que tinha também o objetivo de conformar um campo pedagógico. A ação de propagandistas protestante se fez presente em várias Províncias do país, dentre elas, Pará, Bahia, Maranhão, Sergipe, Pernambuco, Alagoas, Paraíba. Até meados da década de 30 do século XX, instituições protestantes distribuíram aproximadamente dez milhões de impressos de destinação religiosa e escolar. No entanto, a publicação, edição, distribuição, circulação e práticas de leituras são áreas de investigação quase intocadas durante um século pela historiografia educacional e confessional brasileira.

Palavras-Chaves: Protestantismo no Brasil; Circulação de Impressos; Pedagogia Protestante

${ }^{1}$ Doutora em Educação. Professora PPG II Nível 3 da Universidade Tiradentes/UNIT. Integra o Programa de Pós-Graduação em Educação/Mestrado e Doutorado em Educação e leciona a disciplina História da Educação em Cursos de Licenciatura. E-mail: esterfraga@gmail.com. ORCID: https://orcid.org/00000002-4050-767X 


\title{
Brazil, England and Portugal: circulation of protestant prints in northeastern Brazil
}

\begin{abstract}
:
This work presents the action of the British Bible Society and Foreign / BFBS in Brazil, during the 19th century, especially in the Northeast, circulating Protestant prints. The aforementioned text has the financial support of CNPq and integrates the Research Project coordinated by this researcher, entitled Brazil, Portugal and England: circulation of Protestant and others printed during the 1800s. The strategy of distributing prints preceded the organization of schools, with the purpose of implementing definitely Protestantism in Brazil. How this strategy was successful in a country that, at the time, had a mostly illiterate population? What could be seen as a problem was actually the differential. When the colporteur, a street vendor of Protestant prints, arrived in a certain place that people could not read, he proposed the organizing a group and committed to sending a teacher to teach them, who actually was also a missionary. In this way, they mapped the territory of installation of their future churches and schools in Brazil. The hypothesis I defend is that the intervention of Protestant institutions in circulation and dissemination of printed material allowed the definitive insertion of the Protestantism in the country. This work considers the Protestant prints that circulated in Brazil and Portugal from the 1800s as Libraries Protestant Pedagogical, which were used as strategies for the construction of a Protestant Christian civilization, which also had the objective of shaping a pedagogical field. The action of Protestant propagandists it was present in several provinces of the country, among them, Pará, Bahia, Maranhão, Sergipe, Pernambuco, Alagoas, Paraíba. Until the mid-30s of the 20th century, Protestant institutions distributed approximately ten million of printed material for religious and school purposes. However, the publication, editing, distribution, circulation and reading practices are areas of investigation almost untouched during for a century by educational historiography and Brazilian confessional.
\end{abstract}

Keywords: Protestantism in Brazil; Circulation of Prints; Protestant Pedagogy

\section{Brasil, Inglaterra y Portugal: circulación de impresiones protestantes en el noreste de Brasil}

\section{Resumen:}

Este trabajo presenta la acción de la Sociedad Bíblica Británica y Extranjero / BFBS en Brasil, durante el siglo XIX, especialmente en el Nordeste, impresiones protestantes circulantes. El citado texto cuenta con el apoyo económico del CNPq e integra el Proyecto de Investigación coordinado por este investigador, titulado Brasil, Portugal e Inglaterra: circulación de protestantes y otros se imprimieron durante el siglo XIX. La estrategia de distribuir grabados precedió a la organización de las escuelas, con el propósito de implementar definitivamente el protestantismo en Brasil. Cómo tuvo éxito esta estratégia en un país que, en ese momento, tenía una población mayoritariamente analfabeta? Lo que podía verse como un problema era en realidad el diferencial. Cuando llegó el colportor, un vendedor ambulante de grabados protestantes en cierto lugar que la gente no podía leer, propuso la organizar un grupo y comprometerse a enviar un profesor a enséñales, quien en realidad también fue misionero. De esta manera, ellos mapeó en Brasil el territorio de instalación de sus futuras iglesias y escuelas. La hipótesis que defiendo es que la intervención de las instituciones protestantes em La circulación y 
difusión del material impreso permitió la inserción definitiva del Protestantismo en el país. Esta obra considera las estampas protestantes que circuló en Brasil y Portugal desde el siglo XIX como Bibliotecas Pedagógica protestante, que se utilizaron como estrategias para la construcción de una civilización cristiana protestante, que también tenía el objetivo de dar forma a un campo pedagógico. La acción de los propagandistas protestantes estuvo presente en varias provincias del país, entre ellas, Pará, Bahia, Maranhão, Sergipe, Pernambuco, Alagoas, Paraíba. Hasta mediados de los 30 del Siglo $\mathrm{XX}$, las instituciones protestantes distribuyeron aproximadamente diez millones de material impreso con fines religiosos y escolares. Sin embargo, la publicación, Las prácticas de edición, distribución, circulación y lectura son áreas de investigación. casi intacto durante un siglo por la historiografía educativa y Confesionario brasileño.

Palabras llave: Protestantismo en Brasil; Circulación de impresiones; Pedagogía protestante

$\mathrm{Na}$ perspectiva da História Cultural, esse texto está inserido na História da Educação e na História do Livro. Apresenta resultados parciais do projeto intitulado "Brasil, Inglaterra e Portugal e a Circulação de Impressos Protestantes/1818-1884", iniciado em 2012, com o fomento de Bolsa Produtividade em Educação do CNPq e, aprovado pela segunda vez em 2015. Sob a coordenação dessa pesquisadora, esta pesquisa propõe realizar um levantamento de impressos protestantes que circularam no Brasil durante o século XIX, através da Sociedade Bíblica Britânica e Estrangeira/BFBS permitindo uma apreensão da imprensa protestante e sua relação com a História da Educação, estudando-os como estratégias editoriais de difusão e conformação de saberes e práticas religiosas e pedagógicas.

Tem como foco principal mapear o território de ação dos agentes e colportores vinculados à BFBS no país e analisar a relação dessa ação com a instalação de escolas protestantes no Brasil por missionários presbiterianos norte-americanos, vinculados a Junta de Nova York. O trabalho realizado em parceria pelos sujeitos dessas duas instituições possibilitou a organização de uma verdadeira rede de publicação, venda e distribuição de impressos protestantes no território brasileiro durante o século XIX, a qual funcionou como dispositivo de apropriação de um novo modelo cultural, além de possibilitar a implantação de suas igrejas e escolas.

No período de 2013 e de 2015, foram feitas a sistematização, transcrição, tradução e análise de bibliografia e dos relatórios produzidos pelos 34 agentes da BFBS que trabalharam no Brasil no período de 1818 a 1884, que foram coletados por essa pesquisadora em julho de 2012, na Britsh and Foreign Bible Society's Library/ BFBS Archives Indexes/BSAX, pertencente ao acervo da Cambridge University Library (UK). 
Essa investigação tem viabilizado o levantamento da documentação da BFBS e também o reconhecimento da existência de outros documentos e dimensões da investigação a serem explorados no mesmo acervo. O corpus documental coletado é formado por 128 cartas e 60 relatórios expedidos por eles, todos digitalizados por Nascimento $(2010,2015)^{2}$.

Quadro 1. Década e quantidade de documentos (1810-1890)

\begin{tabular}{|c|c|}
\hline DÉCADA & QUANTIDADE DE DOCUMENTOS \\
\hline 1810 & 01 cartas \\
\hline 1820 & 16 cartas \\
\hline 1830 & 17 cartas \\
\hline 1840 & 25 cartas \\
\hline 1850 & 16 cartas \\
\hline 1860 & - \\
\hline 1870 & 02 cartas \\
\hline 1880 & 06 cartas \\
\hline 1890 & 271 documentos \\
\hline TOTAL & \\
\hline
\end{tabular}

Fonte: BFBS Archives Indexes/BSAX. Cambridge: Cambridge University Library, 2010.

Os estudos sobre impressos religiosos dentro da História da Educação têm se intensificado nos últimos anos, apesar de ainda serem escassos. Dentre os pesquisadores que investigam principalmente impressos católicos, encontram-se Elomar Antonio Callegaro Tambara, Antonio Donizetti Sgarbi, Raquel Martins de Assis, Mauro Passos, Urbano Zilles, Raquel Martins de Assis, Valéria Carmelita Santana Souza, Rosemeire Marcedo Costa, Dionísio de Almeida Neto e Ana Luzia Santos. Dentre os que pesquisam impressos protestantes, estão Ephraim de Figueiredo Beda, Lyndon Araújo Santos, Shirley Puccia Laguna, Ester Fraga Vilas-Bôas Carvalho do Nascimento, Alderi Souza de Matos, Micheline Reinaux Vasconcelos, Sandra Cristina da Silva, Nicole Bertinatti, Priscila Mazêo, Mirianne de Almeida e, Tâmara Regina Reis Sales.

\footnotetext{
${ }^{2}$ Essa documentação compõe o acervo da BFBS Archives Indexes/BSAX, que possui cerca de 4.800 correspondências enviadas por correspondentes estrangeiros nos países que trabalhavam (1804-1884).
} 
A divulgação de impressos religiosos chegou ao Brasil durante o Oitocentos através do trabalho de propaganda desencadeado pela Sociedade Bíblica Britânica e Estrangeira e Estrangeira (BFBS) e pela Sociedade Bíblica Americana (ABS). A primeira foi fundada em 1804 e a segunda, em 1816. Eram instituições mundiais que tinham como finalidade a divulgação integral ou parcial da Bíblia na língua vernácula de cada povo. Antes mesmo de estabelecerem agências no Brasil, iniciaram um trabalho de divulgação e propagação das ideias protestantes no país nas primeiras décadas do século XIX expedindo Bíblias e Novos Testamentos através da embaixada inglesa, por portadores diretos, por comerciantes, pelos comandantes de navios que zarpavam dos Estados Unidos. Essas instituições prescreviam o percurso de comunicação dos seus impressos, definindo os temas, os autores, os agentes, e os colportores.

O agente tinha nível superior e era o representante institucional no país que estivesse trabalhando. Já o colportor, no Brasil, se caracterizou como o expedidor e vendedor ambulante de impressos protestantes. Este, geralmente, tinha formação escolar primária. Sua missão era criar polêmica com as autoridades eclesiásticas locais através da imprensa e observar a cidade mais propícia para as futuras instalações de igrejas e escolas protestantes. E, mesmo que não tivesse muita familiaridade com o material que fosse vender, era orientado a demonstrar muito entusiasmo na apresentação.

As sociedades bíblicas eram associações voluntárias, funcionando desde o início do século XIX como instrumentos de intervenção internacional na área religiosa. Eram organizações administrativas pertencentes a comunidades protestantes com o objetivo de manter a propaganda evangélica no seu país e no estrangeiro.

As sociedades voluntárias, ou sociedade de ideias, - maçônicas, patrióticas, literárias, religiosas etc - foram formas modernas de sociabilidade que ofereceram "novos modelos associativos em meio de uma sociedade globalmente organizada em torno de uma estrutura corporativa hierárquica (ordens) e composta na essência por atores sociais coletivos". Como contraponto da sociedade tradicional, do Antigo Regime, aquelas organizações foram "portadoras da modernidade, no sentido de que estruturavam novas formas de organização do social, não centradas sobre os antigos grupos, mas no indivíduo como ator político e social". Eram caracterizadas pelo fato de que "cada um de seus membros terem somente uma relação com as ideias, com os fins". Aquelas novas associações funcionaram como laboratórios democráticos nos quais seus membros se 
educavam pela prática política moderna enquanto indivíduo-cidadão que exercia sua soberania como parte do grupo de eleitores (BASTIAN, 1993, p. 8).

A estratégia de distribuir impressos antecedeu à organização de igrejas e escolas, com a finalidade de implantar definitivamente o Protestantismo no Brasil. Como essa estratégia teve sucesso num país que, na época, possuía uma população analfabeta em sua maioria? O que poderia ser visto como um problema era, na verdade, o diferencial. Quando o colportor chegava num determinado local que as pessoas não sabiam ler, ele propunha a organização de um grupo e se comprometia em enviar um professor para ensiná-los, que, na verdade também era um missionário. Dessa maneira, eles mapearam no Brasil o território de instalação de suas futuras igrejas e escolas. Os resultados iniciais demonstram que a intervenção de instituições protestantes na circulação e difusão de impressos possibilitou a definitiva inserção do Protestantismo no país. O quadro a seguir registra os agentes e seus respectivos locais de atuação.

\section{QUADRO 2 - AGENTES DA BFBS E SEUS RESPECTIVOS LOCAIS DE ATUAÇÃO (1818-1884)}

\begin{tabular}{|l|l|l|}
\hline \multicolumn{2}{|c|}{ AGENTE } & \multicolumn{2}{c|}{ ANO } & \multicolumn{1}{c|}{ Região Sul } \\
\hline John Rudge & 1818 & Rio de Janeiro \\
\hline (...) Boys & 1819 & Rio de Janeiro \\
\hline \multirow{2}{*}{ G. J. Standfast } & 1823 & Rio de Janeiro \\
\cline { 2 - 3 } & 1824 & Rio de Janeiro \\
\hline Edmund Pink & 1825 & Rio de Janeiro \\
\hline (...) Fowles (ou Fowkes) & 1825 & Rio de Janeiro \\
\hline S. R. Mackay & 1826 a 1836 & Rio de Janeiro \\
\hline Stewart Kerr & 1827 & Rio de Janeiro \\
\hline March Brothers \& Co. & 1834 & Rio de Janeiro \\
\hline Wihelm Von Theremin & 1835 & Rio de Janeiro \\
\hline James Thornton & 1836 a 1838 & Rio de Janeiro \\
\hline George Harvey & 1837 & Rio de Janeiro \\
\hline Arthur Maister & 1838 & Rio de Janeiro \\
\hline \multirow{2}{*}{ C. L. Voges } & $-*$ & Santa Catarina \\
\cline { 2 - 3 } & $-*$ & Rio Grande do Sul \\
\hline \multirow{2}{*}{ J. F. Lippold } & 1849 & Petropólis-RJ \\
\hline \multirow{2}{*}{ James Fletcher } & $1853 / 1855$ & Rio de Janeiro \\
\hline Henry Hadley & 1855 & Rio de Janeiro \\
\hline Nathaniel Sands & 1856 & Rio de Janeiro \\
\hline
\end{tabular}




\begin{tabular}{|c|c|c|}
\hline William Elliot & 1856 & São Paulo \\
\hline James Thornton & 1851 & Rio de Janeiro \\
\hline Alexander L. Blackford & $1869 / 1872$ & Rio de Janeiro \\
\hline José M. M. de Carvalho & $1872 / 1874 / 1875$ & Rio de Janeiro \\
\hline Robert Reid Kalley & $1874 / 1875$ & Theresópolis/RJ \\
\hline Edward Lane & 1876 & Campinas/SP \\
\hline J. M. J. dos Santos & 1884 & Rio de Janeiro \\
\hline \multicolumn{3}{|l|}{ Região Norte } \\
\hline G. A. Carruthers & $1821 / 1822$ & Recife \\
\hline Edward Rivers Fletcher & 1822 & Recife \\
\hline \multirow{2}{*}{ Richard Henry Winslow } & 1827 & São Luis \\
\hline & 1828 & São Luis \\
\hline Edward George Parker & $1840 / 1842 / 1846 / 1851$ & Bahia \\
\hline William Dadson & $\begin{array}{l}1840 / 1844 / 1845 / 1846 / \\
1850 / 1851 / 1854 / 1857\end{array}$ & Rio de Janeiro \\
\hline James Henderson & 1840 & Pará \\
\hline James Burnett & 1840 & Maceió-AL \\
\hline Benjamin F. Tuckniss & 1841 & Pernambuco \\
\hline James Hogg & $1845 / 1856$ & Bahia \\
\hline G. Caley & 1870 & Bahia \\
\hline
\end{tabular}

FONTE: BFBS Archives Indexes/BSAX. Cambridge: Cambridge University Library, 2010.

*Não foi possível localizar o ano de atuação devido às dificuldades encontradas na tradução do documento.

No ano de 1818, em um mesmo documento, foram anexadas duas correspondências. A primeira, datada de 16 de dezembro de 1818, foi escrita por Robert Ralston, na Filadélfia, para Joseph Iarn, Secretário Assistente da BFBS, que se encontrava naquela cidade. Ela é composta somente com um parágrafo relatando que está anexando uma carta onde é relatada a disposição de John Rudge em fazer circular as escrituras na América do Sul. 
Estou disposto a juntar em anexo cópia de uma carta recebida do $\mathrm{Sr}$. John Rudge que se encontra no Rio de Janeiro tendo em vista que você pode ver o quanto ele está disposto a promover o grande objetivo de fazer circular as escrituras na América do Sul (Robert Ralston, Filadélfia/Pensivânia - EUA, 16/12/1818).

Depois desta, a seguir, a correspondência anexada foi do dia $1^{\circ}$ de outubro de 1818, escrita por John Rudge que se encontrava no Rio de Janeiro, destinada para Robert Ralston, na Filadélfia. Ele relatou a alegria de ter sido considerado uma pessoa apta para difundir entre os habitantes da América do Sul a Palavra Sagrada, habitantes estes que estariam com desejo de se beneficiar com ela.

Eu não poderia ser mais grato os meus sentimentos, ao ser considerado por um cavalheiro de sua respeitabilidade e reputação honrosa, como uma pessoa apta para difundir entre os habitantes da América do Sul, os livros de valor inestimável se dirigiram a minha remessa pelo Brig. James Murdock, Capitão Charles Bartling e permita-me Senhor, vos garantir, que nenhum esforço faltará de minha parte para distribuí-los de maneira apropriada entre aqueles que são desprovidos das escrituras, e estão desejosos de se beneficiar com elas (John Rudge, Rio de Janeiro, $1 / 10 / 1818)$.

E ainda, fez o relato da dificuldade do alcance dos objetivos, informando que fizera um requerimento às autoridades para que os materiais religiosos pudessem ser transmitidos sem impostos e acreditava que seu pedido seria atendido logo.

Três anos depois, o resumo de uma carta que fora escrita por G. A. Carruthers em Pernambuco, no dia 24 de novembro de 1821, mostrava a curiosidade da população em receber as Sagradas Escrituras. Membros do clero também pediam exemplares e Carruthers foi obrigado a dar as Bíblias que estavam destinadas à Paraíba.

As Bíblias foram todas distribuídas e se for por um motivo melhor do que a curiosidade eu não sei dizer, mas eu nunca testemunhei tanta ansiedade, como a que foi evidenciada por todas as classes para obtêlas. Muitos do Clero requereram e fui obrigado a dar a poucas parcelas às destinadas à Paraíba (G. A. Carruthers, Pernambuco, 24/11/1821).

O resumo de uma carta de Edward Rivers Fletcher para James Miller - Secretário da Sociedade Bíblica Britânica e Estrangeira, datada de Pernambuco, 11 de maio de 1822, relatava que o povo estava ansioso para conhecer aquela nova religião através dos impressos distribuídos pelos membros da BFBS. Registrava também que as Bíblias viam de Londres e que o governo brasileiro autorizara a passagem delas pela alfândega, sem 
cobrança do imposto sendo possível distribuir gratuitamente para as pessoas interessadas. Mas, em alguns casos foram vendidas por 12.000 réis por Bíblia, o equivalendo a 3.7 libras.

Fico feliz em afirmar que sem dúvida pode ser admitido realmente a disposição e ansiedade do povo para receber as cópias das Bíblia. A quantidade que há algum tempo era enviada de Londres, foi autorizada pelo governo para ser despachada pela alfândega livre de impostos e todas as cópias forma distribuídas gratuitamente para multidões de indivíduos, em alguns casos, eles foram de fato vendidas por aquele que tinham recebido e o alto preço de 12.000 réis igual a 3.7 libras era dado por uma bíblia, que sendo ao mesmo tempo uma grande tentação para o homem pobre e uma prova do desejo do homem rico de obter este livro do qual ele anteriormente conhecia tão pouco, esse tão longe de demonstrar qualquer indiferença quanto à posse das escrituras, eu acho que para provar o desejo de obter este livro maravilhoso, mesmo com a despesa de algum sacrifício da satisfação pessoal que poderia ter sido adquirido com a soma assim gasta (Edward Rivers Fletcher, Pernambuco, 11/05/1822).

Ainda no resumo da carta, Fletcher relata os muitos pedidos dos habitantes do Brasil em adquirir as Sagradas Escrituras. Retrata também, a sua felicidade de poder satisfazer o desejo do povo e, consequentemente, o desejo da BFBS. E encerra, mostrando

a preocupação em estar atrapalhando o destinatário, deixando claro que está torcendo para

o sucesso da Missão e, solicita o suprimento dos impressos para a devida distribuição.

Eu tive muitos pedidos urgentes de Bíblias e Testamentos e só me livrei da importunação dos candidatos, mantendo-lhes a expectativa de receber uma carga da Inglaterra para seu uso e garanto-vos que eu deveria estar muito satisfeito por uma oportunidade de atender os desejos do Povo. Eu temo invadir ainda mais o seu tempo valioso e, portanto, encerro todo meu respeito, assegurando-lhes os meus melhores votos para o sucesso do seu importante estabelecimento e solicitando a sua influência para um suprimento de Bíblias e Testamentos para distribuição aqui (Edward Rivers Fletcher, Pernambuco, 11/05/1822).

A correspondência do dia 23 de agosto de 1823, foi escrita no Rio de Janeiro, por E. J. Standfast, destinada ao Secretário Assistente Estrangeiro da BFBS, E. F. Roenneberg, localizado em Londres. Nesta, inicialmente, o Standfast preocupou-se em informar o recebimento das Bíblias e Novos Testamentos, registrando que tinham chegado na hora certa e, que estavam sendo bem cuidadas. Logo após, revelou que era necessário cautela para a execução dos interesses da BFBS, devido à situação política do Brasil e que fizera uma pausa na distribuição de Bíblias entre os amigos do clero. Relatou 
também que o governo, em seu desejo de disseminação da instrução, tornou isentos da taxa de importação àqueles impressos, visto que não eram imorais. Com isso, aumentara o desejo da sociedade em ter acesso àquelas publicações.

\begin{abstract}
A remessa de Bíblias e Novos Testamentos a qual a Sociedade Bíblica Britânica e Estrangeira confidenciou aos meus cuidados, chegou na hora certa e recebeu toda a minha melhor atenção. O estado político do país exige muita cautela para orientar claramente os nossos interesses e depois houve uma pausa cautelosa na minha decisão em distribuir um pouco de cada volume entre os amigos particulares incluindo alguns membros do clero. O governo no desejo ansioso para disseminar a instrução submete admitir livremente isentos de quaisquer taxa de importação e todos os trabalhos impressos não imorais e a avidez do público para obter informação anteriormente negada a eles, aumenta diariamente agindo para o espírito de suas instruções. Eu considero esta decisão adequada. Eu fixei um preço muito baixo - 960 réis para a Bíblia e o Testamento e 320 réis para o Novo Testamento (E. J. Standfast, Rio de Janeiro, 23/08/1823).
\end{abstract}

Já que estavam com o preço baixo, foi despertado o interesse de livreiros em adquirir aqueles materiais para fins lucrativos, mas, o Standfast relata que não aceitou essa venda, pois, o objetivo do preço baixo era de somente identificar os indivíduos que estavam adquirindo aquele material religioso e, obtendo simultaneamente, suas opiniões e interesses em adquirir os livros (Bíblias e Novos Testamentos) e não vendê-los para os lojistas revenderem e lucrarem com o referido material religioso.

Um livreiro queria comprar o conjunto de mim a esse preço, mas como eu sabia que era para lucrar em cima deles - eu rejeitei sua oferta Gostaria apenas de vendê-los à sociedade, tomando o nome das partes e processando e conversando com eles sobre sua opinião sobre os livros e sobre os motivos de seu desejo em possuí-los (E. J. Standfast, Rio de Janeiro, 23/08/1823).

No dia 22 de dezembro de 1827, o Rev. Stewart Kerr, escreveu para John Jackson. $\mathrm{Na}$ carta ele avisa a sua mais nova responsabilidade em fazer parte dessa missão, substituindo o Rev. S. R. MacKay, enquanto este estava passando por alguns problemas de saúde. Além disso, o Rev. Kerr relata que tinha em mãos todas as cartas recebidas por MacKay e confirma o recebimento em segurança das Bíblias e a distribuição das mesmas e mostra que a partir de agora, está tudo sob sua responsabilidade.

Em consequência do mal-estar e outras aflições que Deus designou para ele, meu amigo MacKay já me solicitou para tomar conta de todos os assuntos aqui relacionados com a sua sociedade, e para esta finalidade 
foi entregue a mim as cartas e documentos de todo o tipo relacionados com a atividade, todos os quais tiveram minha total atenção (Stewart Kerr, 22/12/1827).

Na missiva escrita no Rio de Janeiro por James Thornton, dia 12 de abril de 1838 para John Jackson em Londres, é iniciada com o pedido de envio de mais "pequenos livros" para a continuação de suas funções. Logo em seguida, acredito que a numeração trazida seja correspondente à quantidade de Bíblias e Novos Testamentos que ele deseja receber.

Tive o prazer de receber os seus favores de 6 de Fevereiro e agora para informá-lo que estamos totalmente sem pequenos livros, portanto, por favor, envie-nos por um navio.

100 - Extratos de Bíblias \}

100 - Novos Testamentos \} Português

(James Thornton, 12/04/1838)

Na missiva de 4 de junho de 1838, enviada pelo Rev. R. Arthur Maister no Rio de Janeiro, para o Rev. A. Brandram que estava localizado em Londres inicia-se com uma justificativa para o atraso de resposta da carta sobre o recebimento de Bíblias. Além disso, o Rev. Maister acreditava que não conseguiria distribuir as Bíblias, mas no momento da escrita da carta, ele mostra esperança na distribuição seguida de benefícios.

Temo que eu deva ter sofrido a acusação de negligência, mas eu atrasei a responder sua carta para que eu pudesse anunciar a chegada do pacote de Bíblias e testamentos em português, que eu recebi na semana passada em excelentes condições. Acredito que a distribuição da então acabará por ser produtiva de benefícios. Eu duvidei por um momento que não conseguiria encaminhá-las (Arthur Maister, 14/06/1838).

Pelo conhecimento adquirido na longa convivência entre os brasileiros e pela sua importante função nos estabelecimentos comerciais, esta amiga de A. Maister citada acima - que provavelmente também é inglesa - o ajudaria no convencimento dos lojistas para ajudar na distribuição das Bíblias. Uma parte deste material seria cedido gratuitamente a estes comerciantes e, outra parte seria vendida a um preço mínimo, garantido o possível lucro deles. Depois de aventurar a disposição de metade das Bíblias para serem comercializadas pelos lojistas, Maister se propõe a ficar com a outra metade, para casos oportunos e, se possível, uma distribuição nas escolas privadas, mostrando que o interesse não estava apenas na distribuição para as escolas públicas acreditando que assim seria mais fácil o direcionamento dos nativos para os ideais protestantes. 
Eu tenho, portanto, me aventurado a colocar metade do pacote à sua disposição confiando que vou transmitir os desígnios da B.F.B.S. O resto eu reservo para as oportunidades casuais e, especialmente, para a distribuição nas Escolas Privadas e isso em minha opinião, acabará por revelar o modo mais eficaz de direcionar a atenção dos brasileiros para a PALAVRA da Verdade (Arthur Maister, 14/06/1838).

Antes de serem colocados para circulação, os folhetos deveriam receber um acréscimo no preço de $10 \%$ para a sua valorização, mostrando a confiança de que esse material religioso daria certo. Além disso, a gratidão pelo recebimento destes é explícita e é solicitado mais volumes para atender à demanda da cidade.

O Conselho de Controle, tal como a Alfândega pensou adequadamente para cuidar deles, permitindo a sua valorização com o acréscimo de dez por cento, e desde então eles têm colocado em ampla circulação no Interior, pelos Mensageiros da Paz. Eu confio que vai ser um instrumento de grande utilidade. Eu tenho que solicitar para você a bondade de transmitir aos nossos amigos dignos no Porto nossos sinceros agradecimentos, e também solicitar uma nova subvenção dos seus instrutivos pequenos folhetos variados para a demanda da nossa cidade, e que na mesma ocasião, seremos felizes em receber as graças das poucas linhas deles (James Thornton, Rio de Janeiro, 28/03/1839).

As fontes possibilitam afirmar que, além da venda de Bíblias e de Novos Testamentos, dependendo do nível social de determinada região, muitos exemplares eram oferecidos com desconto ou gratuitamente. Portanto, o foco principal era a difusão das Escrituras Sagradas para obtenção de mais adeptos ao Protestantismo, mesmo que para isso, a BFBS não obtivesse lucro em alguns locais.

Nós tivemos realmente feito propostas para os indivíduos residentes nas Províncias mais distantes, permitindo 20 por cento de desconto sobre os preços da cidade, na esperança de obter uma circulação muito maior para a Palavra Sagrada (James Thornton, Rio de Janeiro, 28/03/1839).

Os agentes também recebiam ofertas em formato de impressos, como registrou Thornton.

Recebi um pacote de 1.500 folhetos em português, sem qualquer nota ou carta, para especificar a quantidade, nem para fornecer os nomes dos amigos gentis, a quem somos gratos por esta concessão liberal (James Thornton, Rio de Janeiro, 28/03/1839). 
Ainda na mesma correspondência, James Thornton revela que um pastor que estava residindo na cidade do Rio de Janeiro estava solicitando a sua demissão e diz que é necessária a substituição e dá a sua opinião sobre o novo indivíduo que ocupará o cargo.

Nosso pastor residente nesta cidade enviou a sua demissão, com 6 meses de antecedência, e a Comissão têm escrito para a Casa à Comissão correspondente em Liverpool, nomeando um Candidato a ser aprovado pelo nosso Bispo diocesano de Londres. Eu espero que ao examinar, o capelão permita-me uma sugestão sobre esse ponto: tenha ainda em mente que é uma nomeação a um posto Cristão, que pode exigir dos ministros que possuam uma aptidão especial para defender a Fé Protestante (...), e olhar para o exterior sobre as perspectivas latentes e proeminentes de sua esfera de utilidade, em geral, sem propósito de entrar na discussão de pontos contestáveis: deve ser prudente, sábio, zeloso e um ministro Cristão. Isso meu caro senhor, não é para ser entendido como uma determinação para solicitação, mas deve ser considerado como uma opinião particular minha, e é indicado para a sua discrição e informação (James Thornton, Rio de Janeiro, 28/03/1839).

James Thornton finaliza a missiva registrando o valor dos 1.500 folhetos recebidos juntamente com o valor do frete destacando, certamente, o valor do lucro.

Na correspondência de 27 de maio de 1839, enviada por Edward George Parker, Capelão britânico na Bahia, para o Secretário assistente da BFBS que se localizava em Londres, John Jackson, ele relatada sua preocupação com o desvio do recebimento dos impressos, dando-nos pista sobre alguns dos problemas que eles enfrentavam.

Tenho diante de mim a sua carta de 21 de novembro de 1838, informando que você tinha encaminhado para Stewart Brothers em Liverpool, 12 Bíblias breviárias [breviário = tipo de bíblias que tem que ser lidas diariamente], 12 pacote de Bíblias e 12 pequenos fragmentos do Novo Testamento.

Eu tenho procurado por esse material em todos os navios que tem chegado de Liverpool desde que eu recebi sua carta em janeiro - mas eles não têm chegado ainda à mão - Deve acontecer a mesma falha em toda Inglaterra.

$\mathrm{Eu}$ tive vários pedidos recentemente para bíblias em português - Eu acho que seria aconselhável enviar uma remessa maior.

Assim que eu receber os livros, terei o prazer de comunicar com você novamente (Edward Geo Parker, 27/05/1839).

Na carta do dia 31 de outubro de 1839, Edward George Parker escreve outra carta destinada à John Jackson. 
Tenho o prazer de reconhecer o recebimento do seu favor em 09 de agosto com uma fatura das 12 Bíblias em Português, que em segurança vêm à mão pelo "Cabotiu" com 12 Bíblias breviárias, 12 pacotes de Bíblias e 12 fragmentos do Novo Testamento (Edward Geo Parker, 31/10/1839).

Durante a década de 40, seis agentes atuaram nas Províncias do Rio de Janeiro, Bahia, Alagoas e Pará: Edward Parker, William Dadson, James Henderson, James Burnett, James Hogg e J. F. Lippold. Na década seguinte, Edward Parker, William Dadson e James Hogg, continuavam atuando porém, juntaram-se a eles os agentes James Flecher, Henry Hadley e Nathaniel Sands atuantes no Rio de Janeiro, além de William Elliot e Verqueiro na Província de São Paulo. Na década de 60, Alexander Latimer Blackford foi o único encontrado em atuação, localizado na Província do Rio de Janeiro. Nos anos 70, Blackford ainda atuava, acompanhado a partir de então por G. Caley, José M. Martins de Carvalho, Robert Reid Kalley e Edward Lane, ampliando a atuação para as Províncias da Bahia e São Paulo. Na última década que registra a atuação da BFBS no Brasil, encontramos o agente J. M. J. dos Santos atuando no Rio de Janeiro.

Quando os agentes chegaram ao Brasil com a tarefa específica de divulgar o Evangelho, encontraram um país que possuía grupos favoráveis à sua implantação, como foi o caso dos maçons e republicanos, mesmo considerando as constantes perseguições da Igreja Católica, que viam o Protestantismo como uma ameaça. Esse movimento ocorreu a partir da primeira metade do século XIX, quando os mensageiros de Deus estabeleceram-se no Rio de Janeiro, Maranhão, Bahia, Rio Grande do Sul, Santa Catarina, Pernambuco, Paraíba, Alagoas, entre outros.

O analfabetismo era um obstáculo para conversão baseada na leitura da Bíblia, dificultando inclusive o progresso e ascensão social, ideia firmemente plantada pela corrente liberal. Portanto, a principal aspiração dos missionários era efetivar a leitura da Bíblia para que dessa forma pudessem ser evangelizados. Não era objetivo da Igreja Católica educar os menos favorecidos nem em disseminar a leitura da Bíblia. Os sacerdotes apenas rezavam a missa em latim.

As forças que os missionários encontravam para encarar esse objetivo de evangelizar um país, vinha da crença de que eram iluminados por Deus e que tinha o dom de espalhar sua palavra a todos aqueles que necessitavam. Ou seja, para eles, civilizar significava oferecer àquela sociedade a salvação do espírito e do corpo, através dos seus preceitos religiosos. 
A análise da documentação do projeto que foi desenvolvido tem sido decisiva na decifração das representações, das discussões, soluções de problemas e dos avanços e recuos das ações de agentes britânicos, coloportores e missionários protestantes presbiterianos na área sob sua jurisdição no Brasil. A difusão dos impressos seu deu a partir do momento em que os colportores eram enviados pelos seus respectivos agentes por embarcações com destino ao Brasil, aqui eram recebidos nos portos pelos fiscais da alfândega, instituição portuária responsável pela entrada e saídas de cargas no país. O agente que estava atuando aqui ia buscar tais impressos e como forma de pagamento dos impostos dava parte dos impressos para os fiscais em troca da liberação do material. Com os impressos em mãos, eles agora partiam pela cidade à pregar e distribuir os impressos em casas, hospitais, igrejas e outros lugares onde eram recebidos, nos locais onde eles não podiam ir cabia ao colportor, negociante nativo, partir para as regiões mais distantes do hinterland brasileiro e demonstrar entusiasmo na venda dos impressos em troca do seu pagamento.

Todo o movimento dos agentes tem sido sistemática e regularmente rastreado durante o período em que ficaram vinculados à instituição. Nas cartas, os agentes relataram suas atividades e impressões sobre o Brasil. Por isso, muitos não resistiram e voltaram à pátria, ou morreram vitimados por moléstias, ou seja, descreviam tudo o que acontecia na área sob sua jurisdição.

Ao tomar o discurso religioso dos agentes britânicos como uma fonte para pensar a produção e as próprias representações acerca da religião e da educação escolar no Brasil no período delimitado, tem sido necessário percorrer e considerar esse conjunto de observações sobre os discursos e sobre a escrita, tais fontes como a correspondência produzida por membros de um grupo religioso resultam de uma compreensão ampliada da noção de documento proposta pela História Cultural a qual historiadores de formação e historiadores da Educação brasileira têm considerado.

Esses são alguns exemplos do conteúdo dessa rica e profusa documentação. Pesquisadores do projeto, juntamente com alunos têm publicado capítulos de livro, artigos em periódicos e em anais de eventos, nacionais e internacionais. A execução da pesquisa tem desencadeado a possibilidade de novas propostas de projetos científicos, oferecendo bolsas de Iniciação Científica para alunos de graduação e possibilitando também a orientação de dissertações de mestrado e de doutorado sobre a temática e, 
consequentemente, o desenvolvimento social e econômico de pessoas pertencentes a grupos sociais locais.

\section{REFERÊNCIAS}

AFONSO, José António Martin. Protestantismo e Educação. História de um projeto pedagógico alternativo em Portugal na transição do século XIX. Braga: Universidade do Minho, 2009a.

BASTIAN, Jean-Pierre (Comp.). Protestantes, liberales y francmasones. Sociedades de ideas y modernidad en América Latina, siglo XIX. México: Fondo de Cultura Económica/CEHILA, 1993.

CHARTIER, Roger. A ordem dos livros. Leitores, autores e bibliotecas na Europa entre os séculos XIV e XVIII. 2a ed. Tradução de Mary Del Priori. Brasília: UnB, 1998.

CHARTIER, Roger et LÜSEBRINK, Hans-Jügen (orgs.). Colportage et lecture populaire. Imprimés de large circulation en Europe XVI ${ }^{o}-X I X^{o}$ siècles. Paris: Maison des Sciences de L'Homme, 1996.

DARNTON, Robert. O beijo de Lamourette. Mídia, cultura e revolução. Tradução de Denise Bottmann. São Paulo: Companhia das Letras, 1990.

ESCOBAR, Samuel. "Orígenes del movimiento de Sociedades Bíblicas y su contexto misionológico". In: Revista Lusófona de Ciência das Religiões, ano IV, 2005, n 7/8, p. 21-30.

NASCIMENTO, Ester Fraga Vilas-Bôas Carvalho do. A Teoria sobre Associações Voluntárias como Matriz Interpretativa das Instituições Escolares Protestantes. In: Libânia Xavier; Elomar Tambara e Antoni Carlos Ferreira Pinheiro. (Org.). História da Educação no Brasil: matrizes interpretativas, abordagens e fontes predominantes na primeira década do século XXI. Espírito Santo: EDUFES, 2011 a, v. 5, p. 355-377.

NASCIMENTO, Ester Fraga Vilas Boas Carvalho do; NASCIMENTO, Jorge. Carvalho do; PINTO, Dayler Antonio Neves. Circulação de impressos protestantes entre Brasil e Portugal. In: Anais do $\mathbf{1 9}^{\circ}$ Encontro de Pesquisa Educacional do Norte e Nordeste. João Pessoa: EDUFPB, 2009, p. 1-11.

NASCIMENTO, Ester Fraga Vilas-Bôas Carvalho do. "Brasil e Portugal: circulação de impressos protestantes". In: VII Congresso Luso-Brasileiro de História da Educação: cultura escolar, migrações e cidadania. Porto: Universidade do Porto, 2008, p. 1-12.

NASCIMENTO, Ester Fraga Vilas-Bôas Carvalho do. Educar, curar, salvar. Uma ilha de civilização no Brasil tropical. Maceió: EDUFAL; Aracaju: UNIT, 2007.

NASCIMENTO, Ester Fraga Vilas-Bôas Carvalho do. "Instituições, editoras e impressos protestantes no Brasil dos Oitocentos". In: Anais Eletrônicos do VI 
Congresso Luso-Brasileiro de História da Educação: Percursos e Desafios da Pesquisa e do Ensino de História da Educação. Uberlândia: EDUFU, 2006, p. 1-13.

NASCIMENTO, Jorge. Carvalho do; NASCIMENTO, Ester Fraga Vilas Boas Carvalho do. Correspondência e redes de sociabilidade. In: Anais do IX Congresso Ibero Americano de História da Educação Latino Americana. Rio de Janeiro: UERJ, 2009, p. $1-10$.

SANTOS, Luís Aguiar. "Evolução da presença em Portugal da Sociedade Bíblica. De agência britânica a instituição de utilidade pública”. In: Revista Lusófona de Ciência das Religiões, ano IV, 2005, nº 7/8, p. 51-61.

SGARBI, A. D. Bibliotecas pedagógicas católicas: estratégias para construir uma "civilização cristã" e conformar o campo pedagógico através do impresso (1929-1938). São Paulo: PUC, 2001.

THE BRITISH AND FOREIGN BIBLE SOCIETY. Rules for the Guidance of Translator, Revisers \& Editors, Working in Connection wiht the British and Foreign Bible Society. London: The British and Foreign Bible Society, 1906.

TOCQUEVIlle, Alexis de. A democracia na América. Sentimentos e opiniões. v. 2.

São Paulo: Martins Fontes, 2000.

WEBER, Max. Ensaios de Sociologia. $2^{a}$ ed. Rio de Janeiro: Zahar, 1971. 